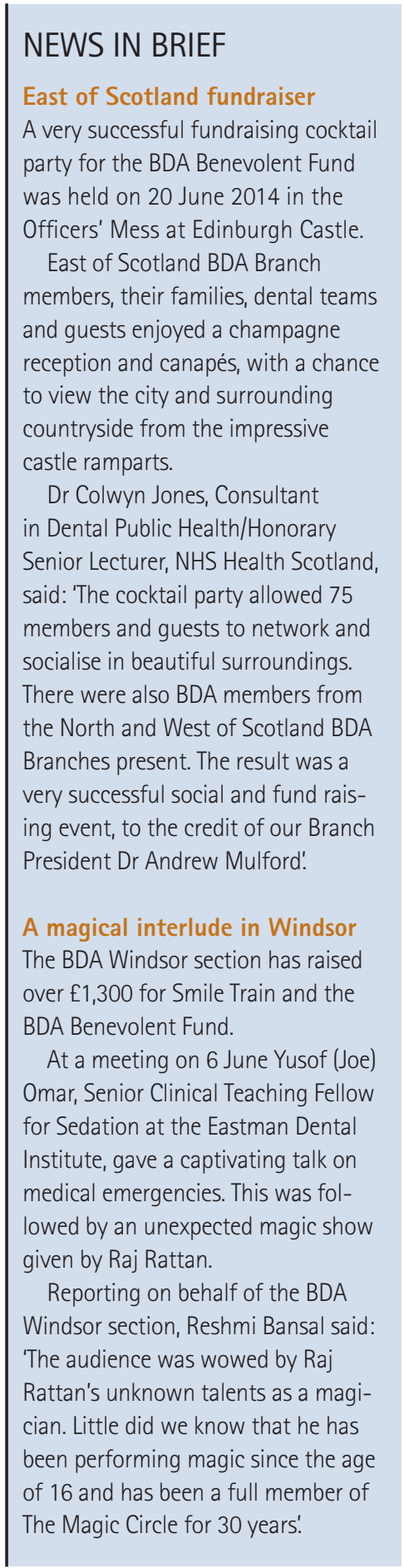

\section{PROFESSOR GEOFFREY HOWE}

We are sad to report that Professor Geoffrey L. Howe has died.

Professor Howe was the first to be appointed as Professor of Oral Surgery in the UK at Newcastle at the age of 35 . He was also VicePresident of the British Dental Association (BDA) in 1979. In 2002 a review of his memoir, Reflections of a fortunate fellow, was published in the $B D J$.

An obituary will follow in a future issue.

\section{A DENTIST'S LIFE}

Tu usually get up between 6:45 am and 7 am depending on how much work I have to do. After getting dressed, I usually do some work - either uni assignments, medico-legal or article writing until it is time to get to work.

I am an associate at Cudworth Dental Surgery in Barnsley and Croft House Dental Practice in Rotherham. I drive to work, usually listening to Radio 4 which I find keeps me up to date with the world. It gives me my daily dose of sporting trivia so that I can just about hold a conversation with a patient if they want to talk about football. Breakfast is usually a cereal bar.

\section{Working week}

I spend three days a week at Cudworth doing private dentistry and two days a week in Maltby in Rotherham treating patients on the NHS. I also work two late nights in Barnsley which is hard work but rewarding because it means patients get a lot of flexibility and I can fit in long appointments for big cases.

I really like the distinction of working at two completely different practices. At Barnsley, I typically treat patients with low dental needs and high motivation, who value the extra time you can spend treating them. Cudworth is a sedation practice, so many of my patients there like to have IV sedation or RA sedation which I really love doing. It is such a nice way to treat nervous patients.

In Rotherham, the patients are mainly from Maltby itself which is very deprived. Typically every new patient starts off with an acute episode which hopefully will lead them onto the road of getting back to good oral health. Along with my principal there, we set up an oral health educator who is one of the long-standing dental nurses at the practice, and really helps get patients on side. Sadly this is a limited resource as there is no extra funding for it, so we selffund it. It makes a real difference though so in my mind is worth it.

\section{DENTISTRY IS AN AMAZING CAREER}

Alexander Holden, 26, is a dental surgeon, writer and expert witness. An associate in Sheffield, Alex is about to finish a Master's in Medical Law and is due to complete a Master of Dental Public Health in 2015. He writes regularly in the dental press, is active within the BDA Young Dentists Committee and is engaged to Viki, also a dentist.

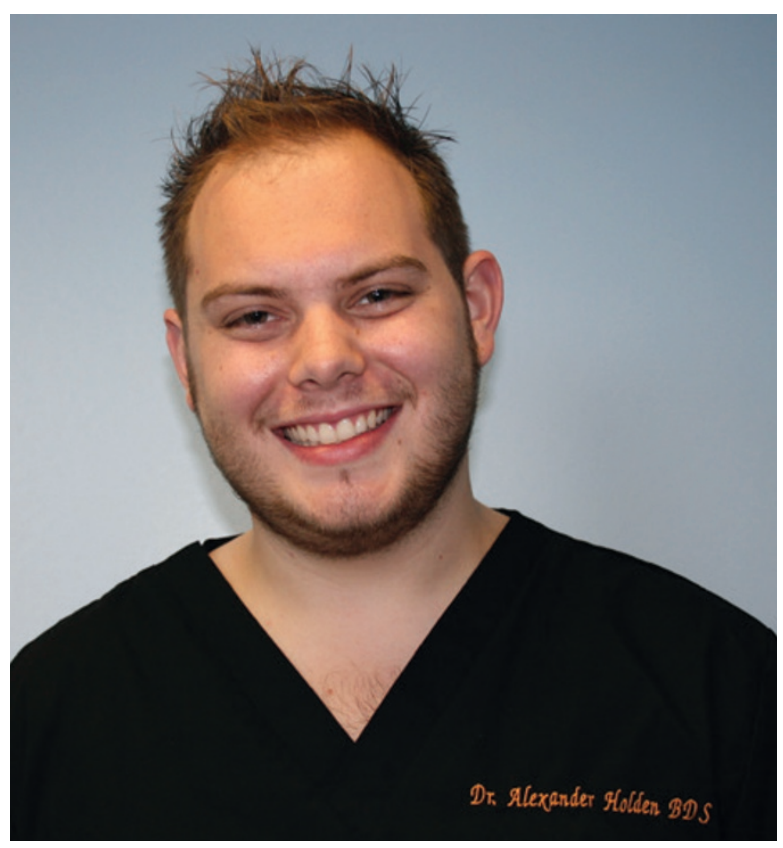

'I feel that my postgraduate degree courses have made me a better dentist, which is in some ways strange because they are non-clinical subjects.'

I really like both of the dental teams I work with; I am lucky to work with two sets of really nice people who I get on with. It makes the day run smoothly when you are alongside nice people.

\section{A family of medics}

I come from a family where the profession of choice is to become a doctor; there are nine medics. Having decided that medicine would have been too much of a path previously trodden, I thought dentistry might be good fun. I am not ashamed to admit that I went into dentistry for completely the wrong reasons. I wanted a lifestyle that was similar to that which I was accustomed to and thought that dentistry might be interesting. I am lucky that I do genuinely enjoy what I do - the financial reward is nice, but very much secondary to feeling good about your work. I'm not very good at coping with 